\title{
A robust and versatile signal-on fluorescence sensing strategy based on SYBR Green I dye and graphene oxide
}

This article was published in the following Dove Press journal:

International Journal of Nanomedicine

22 December 2014

Number of times this article has been viewed

\section{Huazhang Qiul,* \\ Namei $\mathrm{Wu}^{\mathrm{l}, *}$ \\ Yanjie Zheng' \\ Min Chen ${ }^{2}$ \\ Shaohuang Weng' \\ Yuanzhong Chen ${ }^{3}$ \\ Xinhua Lin'}

'Department of Pharmaceutical Analysis, Faculty of Pharmacy, Fujian Medical University, Fuzhou, People's Republic of China; ${ }^{2}$ Department of Orthopedic Surgery, Affiliated Union Hospital of Fujian Medical University, Fuzhou, People's Republic of China; ${ }^{3}$ Fujian Institute of Hematology, The Affiliated Union Hospital of Fujian Medical University, Fuzhou, People's Republic of China

*These authors contributed equally to this work
Correspondence: Shaohuang Weng Department of Pharmaceutical Analysis, Faculty of Pharmacy, Fujian Medical University, I Xue Yuan Road, University Town, FuZhou, Fujian 350I08, People's Republic of China

Email shweng@fjmu.edu.cn

Yuanzhong Chen

Fujian Institute of Hematology, The Affiliated Union Hospital of Fujian Medical University, 29 Xinquan Road, Fuzhou City, Fujian 35000I, People's Republic of China

$\mathrm{Tel}+8659183351966$

Fax +86 59I 8332 4II6

Email chenyz@mail.fjmu.edu.cn

\begin{abstract}
A robust and versatile signal-on fluorescence sensing strategy was developed to provide label-free detection of various target analytes. The strategy used SYBR Green I dye and graphene oxide as signal reporter and signal-to-background ratio enhancer, respectively. Multidrug resistance protein 1 (MDR1) gene and mercury ion $\left(\mathrm{Hg}^{2+}\right)$ were selected as target analytes to investigate the generality of the method. The linear relationship and specificity of the detections showed that the sensitive and selective analyses of target analytes could be achieved by the proposed strategy with low detection limits of 0.5 and $2.2 \mathrm{nM}$ for MDR 1 gene and $\mathrm{Hg}^{2+}$, respectively. Moreover, the strategy was used to detect real samples. Analytical results of MDR1 gene in the serum indicated that the developed method is a promising alternative approach for real applications in complex systems. Furthermore, the recovery of the proposed method for $\mathrm{Hg}^{2+}$ detection was acceptable. Thus, the developed label-free signal-on fluorescence sensing strategy exhibited excellent universality, sensitivity, and handling convenience.
\end{abstract}

Keywords: fluorescence, turn-on, SYBR Green I, graphene oxide, multidrug resistance protein 1 gene, $\mathrm{Hg}^{2+}$

\section{Introduction}

Fluorescence is a common analytical method facilitated by modern testing requirements and developments; it exhibits simple operation, time efficiency, sensitivity, selectivity, and potential for high-throughput bioanalysis. ${ }^{1-4}$ Several fluorescent techniques have been developed to detect various target analytes. Fluorescent sensors based on fluorescence dyes, such as fluorescein isothiocyanate and FAM labels, have been a general routine for biological applications, especially imaging and assays. ${ }^{5,6}$ Semiconductor quantum dots and metal clusters with adjustable emission wavelengths have also been used for DNA and protein detection. ${ }^{5-9}$ Unfortunately, most of the reported biosensors often require label modifications, which increases difficulty in detection, operation costs, and experimentation time. ${ }^{9}$ The development of robust, label-free, and sensitive methods for sensing target molecules through fluorescence is desiderated. ${ }^{2,7,10}$ SYBR Green I (SGI) can be used as a probe to fabricate label-free fluorescent sensors. ${ }^{2,10,11}$ SGI preferentially binds to double-stranded DNA (dsDNA), but stains single-stranded DNA (ssDNA) with weak performance. The resultant dsDNA-SGI complex emits green light at $\lambda_{\max }=520 \mathrm{~nm}$, which is much higher than the ssDNA SGI system. Thus, SGI is widely used to develop label-free fluorescent sensors for biomolecular detection (eg, real-time quantitative reverse transcription polymerase chain reaction). However, because of the intrinsic signal of SGI in the absence of the target, the signal-to-background ratio of fluorescent sensors remains insufficiently high to make the analytical performance 
high enough. Thus, there is an urgent demand for developing universal fluorescent sensors based on SGI with improved sensitivity and specificity. ${ }^{10,12}$

Graphene oxide (GO) is a 2D nanomaterial commonly used as an ideal amplification platform for biosensors because of its enhanced electronic properties, good biocompatibilities, and large surface area. ${ }^{12-15}$ In addition, GO interacts with ssDNA by $\pi-\pi$ stacking interactions between nucleotide bases and GO; however, this material rarely interacts with rigid dsDNA or aptamer target complexes. ${ }^{15-17}$ Thus, the fluorescence of dye-labeled ssDNA will be completely quenched through fluorescence resonance energy transfer upon binding to GO surface. Therefore, GO is an excellent signal-tobackground ratio enhancer to improve the performance of fluorescent methods based on its features. ${ }^{18}$ Free SGI in the solution is also adsorbed on the GO surface because of the absorptivity of GO, thereby eliminating the SGI-generated blank fluorescence. In contrast to traditional fluorescent methods based on direct applications of SGI, ${ }^{10}$ the use of GO as a quenching platform amplifies the signal-to-background ratio to improve the performance of SGI-based label-free fluorescent sensors and is a great attraction.

Multidrug resistance protein 1 (MDR1) gene is associated with the primary drug resistances of tumors. High expression levels of MDR1 indicate that tumor cells have low sensitivity to chemotherapy. Detection of MDR1 gene probes the sensitivity and tolerance of tumors to chemotherapy drugs and predicts the curative effect of chemotherapy by prognosis evaluation. ${ }^{19}$ Clinical methods, such as fluorescence in situ hybridization ${ }^{20}$ and real-time quantitative reverse transcription polymerase chain reaction ${ }^{21}$ have been used to diagnose MDR1. However, some limitations in the reported methods include complicated, expensive, and time-consuming operations. Thus, a facile and effective method should be developed to detect MDR1 gene. In this study, a robust and versatile signal-on fluorescent strategy was fabricated to detect MDR1 gene using SGI dye and GO as signal reporter and signal-to-background ratio enhancer, respectively. The strategy relied on the switching fluorescence of SGI because of the selective insertion of dsDNA and release of DNA complex from GO to stimulate signals (Figure 1). Initially, SGI dyes and DNA capture probes (CPs) were adsorbed on GO surface via hydrophobic and $\pi-\pi$ interactions; GO quenched SGI fluorescence to a low level. In the presence of target sequences, the competitive hybridization of the sequences with DNA CPs transform ssDNA into a DNA duplex structure. Free SGI intercalates with a section of dsDNA to facilitate release from GO surface. The fluorescence intensity of SGI is markedly enhanced in contrast to the low background signal. Thus, quantitative analysis of MDR1 gene can be performed by using GO as a signalto-background ratio enhancer and SGI as a signal reporter. Furthermore, a similar procedure based on the formation of hairpin probes from the $\mathrm{CP}$ was developed through $\mathrm{T}-\mathrm{Hg}-\mathrm{T}$ reaction to mercury ion $\left(\mathrm{Hg}^{2+}\right)$, a serious environmental pollutant, to verify method versatility. This strategy is useful for straightforward, sensitive, and economical detection of diverse specific targets because of its generality and practical maneuverability.

\section{Experimental section}

\section{Materials and reagents}

All the oligonucleotides used in this work were synthesized and purified by TaKaRa Biotechnology (Dalian) Co., Ltd., People's Republic of China. Their sequences are as follows:

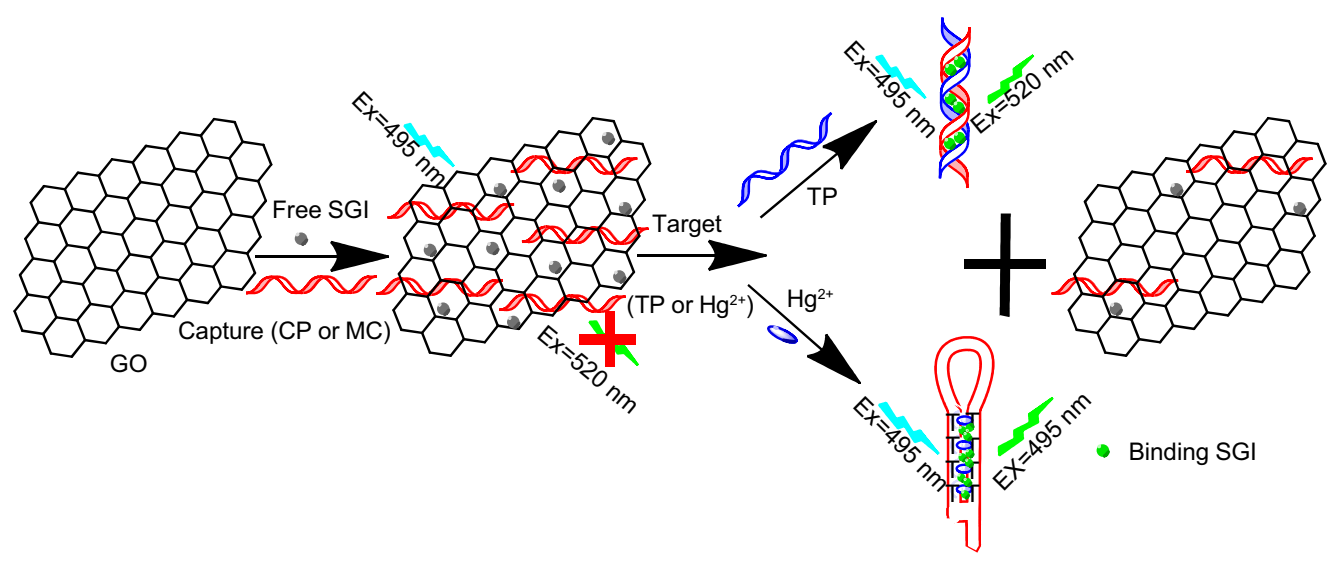

Figure I Representation of the signal-on fluorescence sensing strategy for MDRI gene and $\mathrm{Hg}^{2+}$ based on SGI dye and GO.

Abbreviations: MDRI, multidrug resistance protein I; $\mathrm{Hg}^{2+}$, mercury ion; SGI, SYBR Green I; GO, graphene oxide; CP, capture probe; TP, target probe; MC, mercury captures. 
1) the oligonucleotides for MDR1 detection: CP: 5'-CCG GAA ACA TCC AGC ATA GG-3' Target probe (TP): $5^{\prime}$-CCT ATG CTG GAT GTT TCC GG-3'

One-based mismatch DNA (named as NDR2):

5'-CCT ATG CT T GAT GTT TCC GG-3'

One-based mismatch DNA (named as NDR2):

5'-CAT ATG CT T GAT $\boldsymbol{A}$ TT TCC GG-3'

Non-complementary DNA (Non):

5'-AT AgT gAT AAC gCT AgC TgCA-3'

2) the $\mathrm{CP}$ for $\mathrm{Hg}^{2+}$ detection (mercury captures $[\mathrm{MC}]$ ):

5'-CATTCTTTCTTCCCCTTGTTTGTTTG-3'

SGI $(10,000 \times)$ was purchased from Beijing Dingguo Biotechnology Co., Ltd. (Beijing, People's Republic of China). The received SGI was diluted to $500 \times$ with dimethyl sulfoxide to make SGI stock solution, whose concentration was $19.8 \mu \mathrm{M} .{ }^{10}$ Mercuric chloride $\left(\mathrm{HgCl}_{2}\right), \mathrm{NiCl}_{2} \cdot 6 \mathrm{H}_{2} \mathrm{O}$, $\mathrm{BaCl}_{2}, \mathrm{CrCl}_{3}, \mathrm{PbAc}_{2}, \mathrm{MnAc}_{2}, \mathrm{CoAc}_{2}$ were all provided by Aladdin Reagents Co., Ltd (Shanghai, People's Republic of China). Graphite flake (325 mesh) was purchased from Nanjing XFNANO Materials Tech Co., Ltd (Nanjing, People's Republic of China). All reagents were of analytical grade and the water used throughout all experiments was purified through a Millipore system (Merck Millipore, Billerica, MA, USA). Binding buffer used for T-Hg-T reaction in $\mathrm{Hg}^{2+}$ detection and hybridization buffer used for MDR1 detection are phosphate buffered saline consisting of $10 \mathrm{mM} \mathrm{Na}_{2} \mathrm{HPO}_{4}$, $10 \mathrm{mM} \mathrm{NaH}_{2} \mathrm{PO}_{4}, 0.2 \mathrm{M} \mathrm{NaCl}(\mathrm{pH}=7.4)$.

\section{Assay procedures}

GO was synthesized from graphite flake by an improved Hummers method. ${ }^{22}$ The CPs (CP $50 \mathrm{nM}$ or MC $80 \mathrm{nM}$ ) were mixed with GO $(2 \mu \mathrm{g} / \mathrm{mL})$ and $8 \mu \mathrm{L}$ SGI stock solution to a total volume of $200 \mu \mathrm{L}$. Then, the mixture was placed at room temperature 10 minutes. Following that, various amounts of target analytes ( $\mathrm{TP}$ or $\mathrm{Hg}^{2+}$ ) were added and incubated for 1 hour at specific temperatures $\left(40^{\circ} \mathrm{C}\right.$ for MDR 1 and $27^{\circ} \mathrm{C}$ for $\mathrm{T}$-Hg-T reaction). Immediately, fluorescence measurements were performed.

\section{Apparatus and measurement}

All the fluorescence measurement in this paper was performed by a Cary Elipse Fluorescence Spectrophotometer (Agilent Technologies, Santa Clara, CA, USA). The sample cell was a $350 \mu \mathrm{L}$ quartz cuvette. The excitation wavelength and emission wavelength were $495 \mathrm{~nm}$ and $520 \mathrm{~nm}$ respectively. Both the excitation and emission slits were set at $5 \mathrm{~nm}$. Atomic force microscopy (AFM) images were obtained on

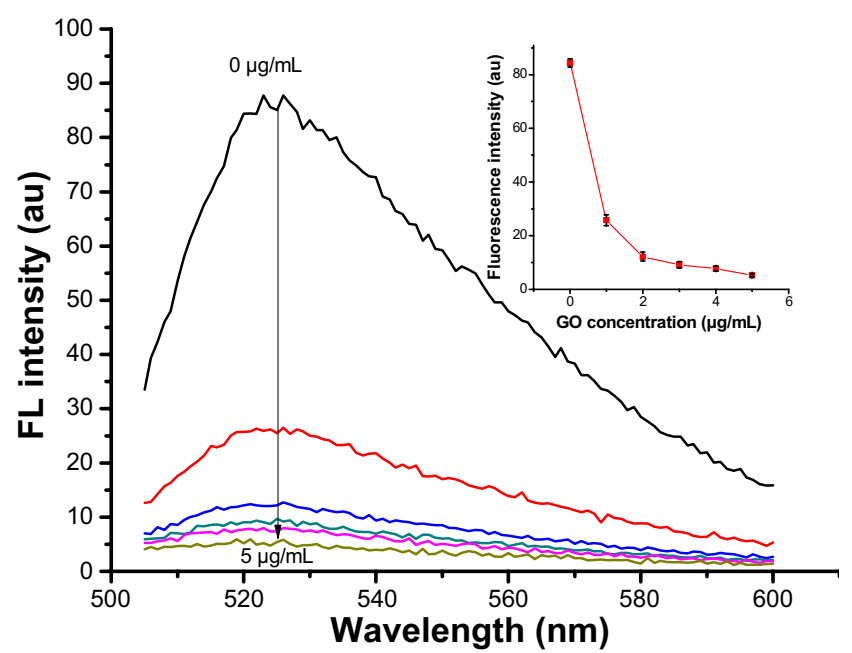

Figure 2 Influence of different concentrations of GO on fluorescence intensity without target analytes.

Notes: Inset shows the relationship of $\mathrm{GO}$ and fluorescence intensity. The concentrations of $\mathrm{SGl}$ and $\mathrm{CP}$ in the test were $0.79 \mu \mathrm{M}$ and $50 \mathrm{nM}$, respectively. Error bars were the standard deviation of the three replicate determinations. Abbreviations: GO, graphene oxide; SGI, SYBR Green I; CP, capture probe; FL, fluorescence; au, arbitrary units.

a Bruker Multimode 8 SPM (Bruker Corporation, Billerica, MA, USA) system in tapping mode.

\section{Results and discussion Optimization of sensing conditions Effectiveness of GO content}

To confirm the quenching effectiveness of $\mathrm{GO}$ and improve the signal-to-background ratio, SGI quenching for the MDR1 detection system was tested to analyze the optimization of GO conditions. Figure 2 reveals that the fluorescence intensity significantly decreased with increased GO concentration, and was almost quenched when the GO concentration was $2 \mu \mathrm{g} / \mathrm{mL}$. The adsorption of GO for SGI and ssDNA was proved by using AFM, as shown in Figure 3. Figure 3A shows that the thickness of $\mathrm{GO}$ is about $1.2 \mathrm{~nm}$. Figure 3B illustrates that the thickness of GO-SGI complex is about $2.0 \mathrm{~nm}$, the thicker height might be due to the adsorbed SGI on the surface of GO. With the DNA adsorption on the surface of GO, Figure 3C illustrates that the increased thickness is about $2.8 \mathrm{~nm}$, which is in accord with the reported work. ${ }^{15}$

The effectiveness of GO concentration to the enhancement of signal-to-background ratio for the detection system was further investigated. The effects of GO concentration on the detected fluorescence in the presence and absence of target MDR1 sequences were compared in a $50 \mathrm{nM} \mathrm{CP}$ system. The signals gradually decreased with increased GO concentration (Figure S1A in Supplementary Materials). With $F_{0}$ and $F$ as the respective fluorescence intensities of SGI at 

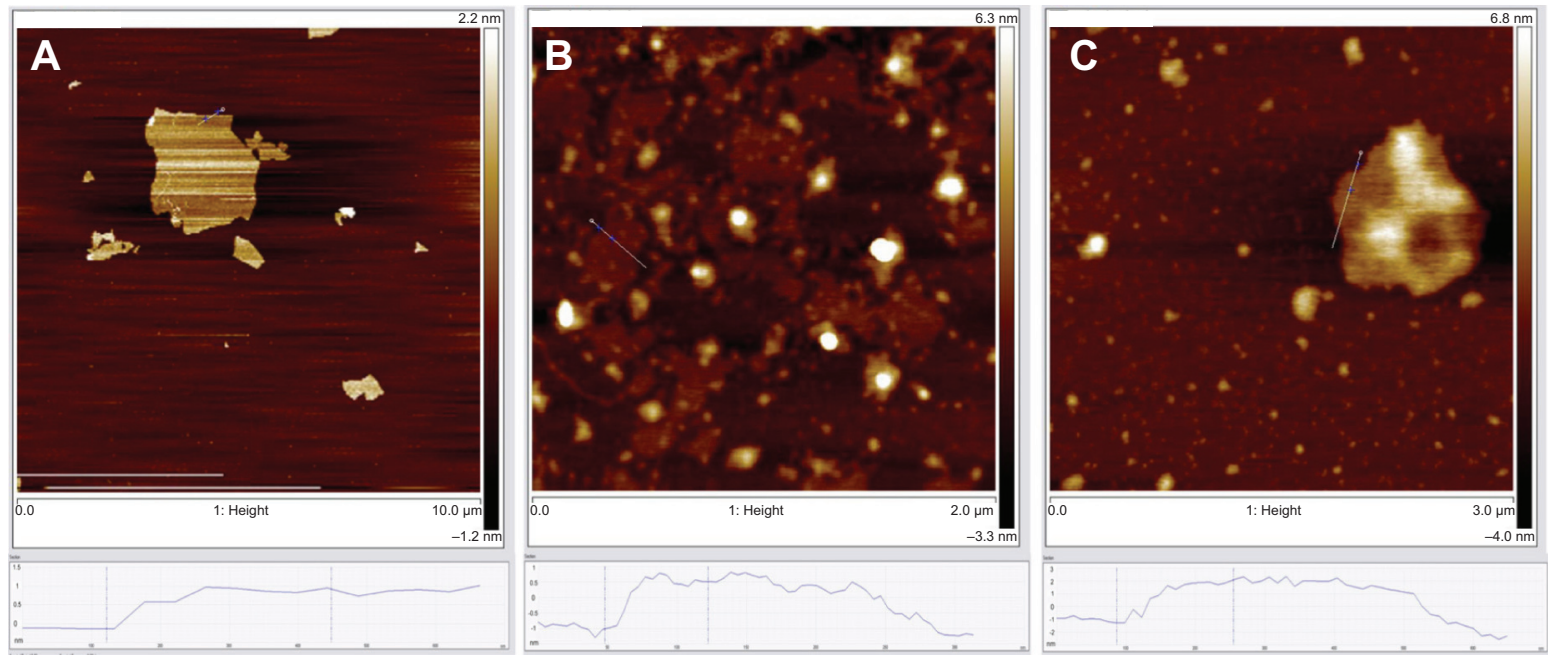

Figure 3 AFM height images of (A) GO sheets, (B) GO and SGI complex, and (C) GO and ssDNA complex on mica substrates. Abbreviations: GO, graphene oxide; SGI, SYBR Green I; AFM, atomic force microscopy; ssDNA, single-stranded DNA.

$520 \mathrm{~nm}$ in the absence and presence of target MDR1 sequences, $F / F_{0}$ increased with GO concentration (Figure S1B). A slow growth amplitude occurred for $\mathrm{GO}$ concentrations greater than $2 \mu \mathrm{g} / \mathrm{mL}$, in which $F / F_{0}=8.2$ was high enough to sensitively quantify the target. The continuous increase in $F / F_{0}$ for GO concentrations higher than $2 \mu \mathrm{g} / \mathrm{mL}$ was mainly attributed to a sufficiently low $F_{0}$. The corresponding values of $\Delta F=$ $F-F_{0}$ were also compared. Figure $\mathrm{S} 1 \mathrm{C}$ indicates that $\Delta F$ was almost kept constant with increased GO concentration from $0 \mu \mathrm{g} / \mathrm{mL}$ to $2 \mu \mathrm{g} / \mathrm{mL}$. $\Delta F$ values for $\mathrm{GO}$ concentrations higher than $2 \mu \mathrm{g} / \mathrm{mL}$ were much lower than those for GO concentrations from $0 \mu \mathrm{g} / \mathrm{mL}$ to $2 \mu \mathrm{g} / \mathrm{mL}$. Given the results of $\Delta F$ and $F / F_{0}$, the GO concentration was selected to be $2 \mu \mathrm{g} / \mathrm{mL}$ for analytical applications.

\section{Effectiveness of SGI concentration}

Optimization of SGI concentration in the detection system was investigated. A $200 \mu \mathrm{L}$ MDR1 gene detection system was used to analyze the changes in $F / F_{0}$ for different SGI concentrations. Figure 4 reveals that $F / F_{0}$ continuously increases until the volume of SGI stock solution reaches $8 \mu \mathrm{L}$, and slightly decreases thereafter. Thus, the optimum SGI volume was selected to be $8 \mu \mathrm{L}$ for $200 \mu \mathrm{L}$ detection systems. The SGI volume corresponds to an SGI concentration of $0.79 \mu \mathrm{M}$ in $200 \mu \mathrm{L}$, which optimizes the increase in $F / F_{0}$.

\section{Effectiveness of assay time}

To determine the assay time, the monitoring of the $F / F_{0}$ as a function of time was studied. SGI quenching for the $\mathrm{Hg}^{2+}$ detection system was tested to analyze the optimization of assay time. Figure 5 shows the gradually increased $F / F_{0}$ due to the increased time. The binding of ssDNA probe and target caused the gradual desorption of probe from the surface of GO. Combined with the embedding of SGI, the fluorescence gradually increased. From the result of the monitoring of the time dependent fluorescence changes, it illustrated that 60 minutes was the most appropriate reaction time for the reaction. Thus, an incubation time of 1 hour was adopted for the assay time.

\section{Sensing performance of MDRI gene and $\mathrm{Hg}^{2+}$}

To confirm the performance of the detection capability of the proposed fluorescence sensing strategy, two different systems of MDR1 gene (TP) and $\mathrm{Hg}^{2+}$ were applied. Figure 6 shows that the fluorescence intensities increase with TP or

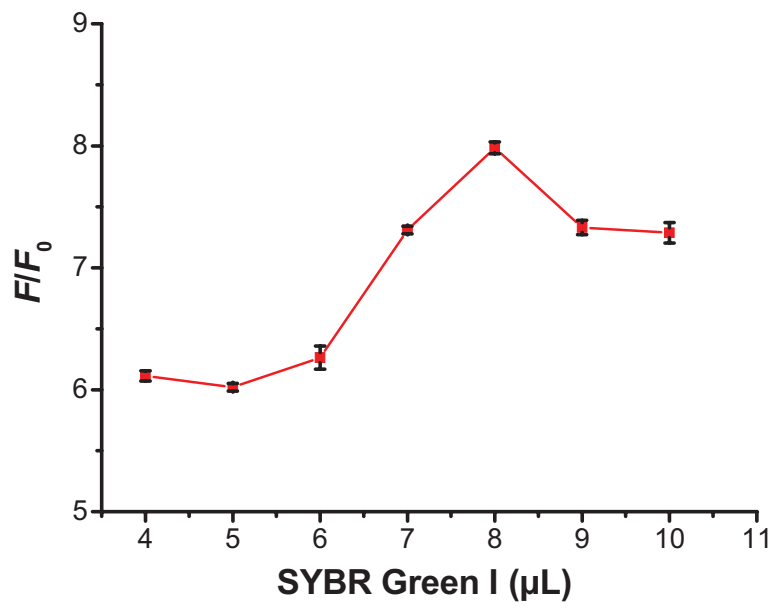

Figure 4 Effects of various volumes of SYBR Green I on $F / F_{0}$ in the absence and presence of $10 \mathrm{nM}$ target DNA.

Notes: The concentration of graphene oxide was $2.0 \mu \mathrm{g} / \mathrm{mL}$. Error bars represent standard deviations of measurements $(n=3)$. 


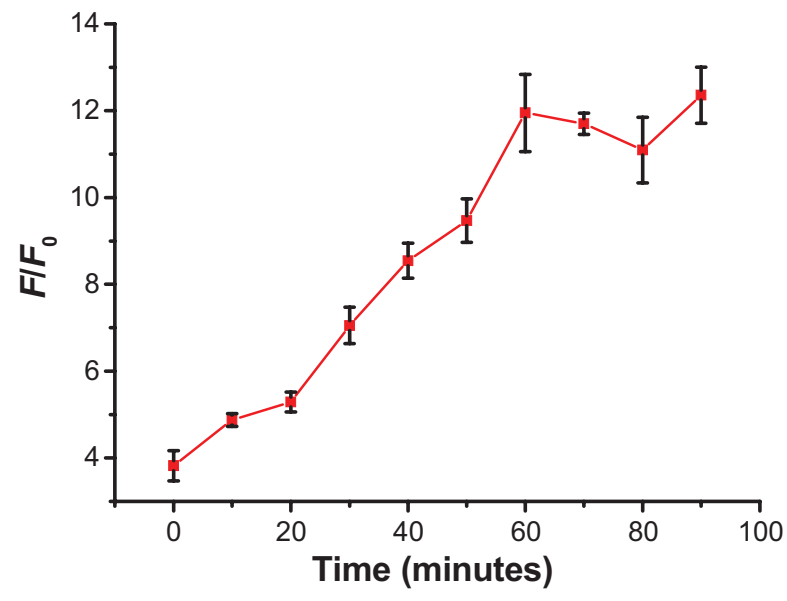

Figure 5 Effects of reaction time of SYBR Green I SGI on $F / F_{0}$ in the absence and presence of $1.2 \mu \mathrm{M} \mathrm{Hg}^{2+}$ in the test conditions of $8 \mu \mathrm{L} \mathrm{SGI}, 80 \mathrm{nM} \mathrm{MC}$, and $2 \mu \mathrm{g} / \mathrm{mL}$ graphene oxide.

Note: Error bars represent standard deviations of measurements $(n=3)$.

Abbreviations: $\mathrm{Hg}^{2+}$, mercury ion; MC, mercury captures; SGI, SYBR Green I.
$\mathrm{Hg}^{2+}$ concentration. Addition of TP or $\mathrm{Hg}^{2+}$ induced a turn-on fluorescence of SGI. For the TP system, $F-F_{0}$ increased with the TP concentration increased in the range of $0 \mathrm{nM}$ to $1,000 \mathrm{nM}$. Furthermore, a good linear relationship between $F-F_{0}$ and TP concentration was illustrated in the range of $0 \mathrm{nM}$ to $50 \mathrm{nM}$ (Figure 6). This result suggested that quantitative assays for TP concentrations could be obtained. The calibration plot of linear equation is given as:

$$
y=7.4922 C_{T P(n M)}+4.6862 \text { with } R=0.9902 .
$$

The limit of detection (LOD) was found to be $0.5 \mathrm{nM}$ based on $3 \sigma$ /slope, where $\sigma$ is the standard deviation of the blank sample. The LOD was much lower than the reported DNA sensor ( $\mathrm{LOD}=2.3 \mathrm{nM}$ ) based on single-walled carbon nanotubes as the quencher platform. ${ }^{23}$ Furthermore, the label-free
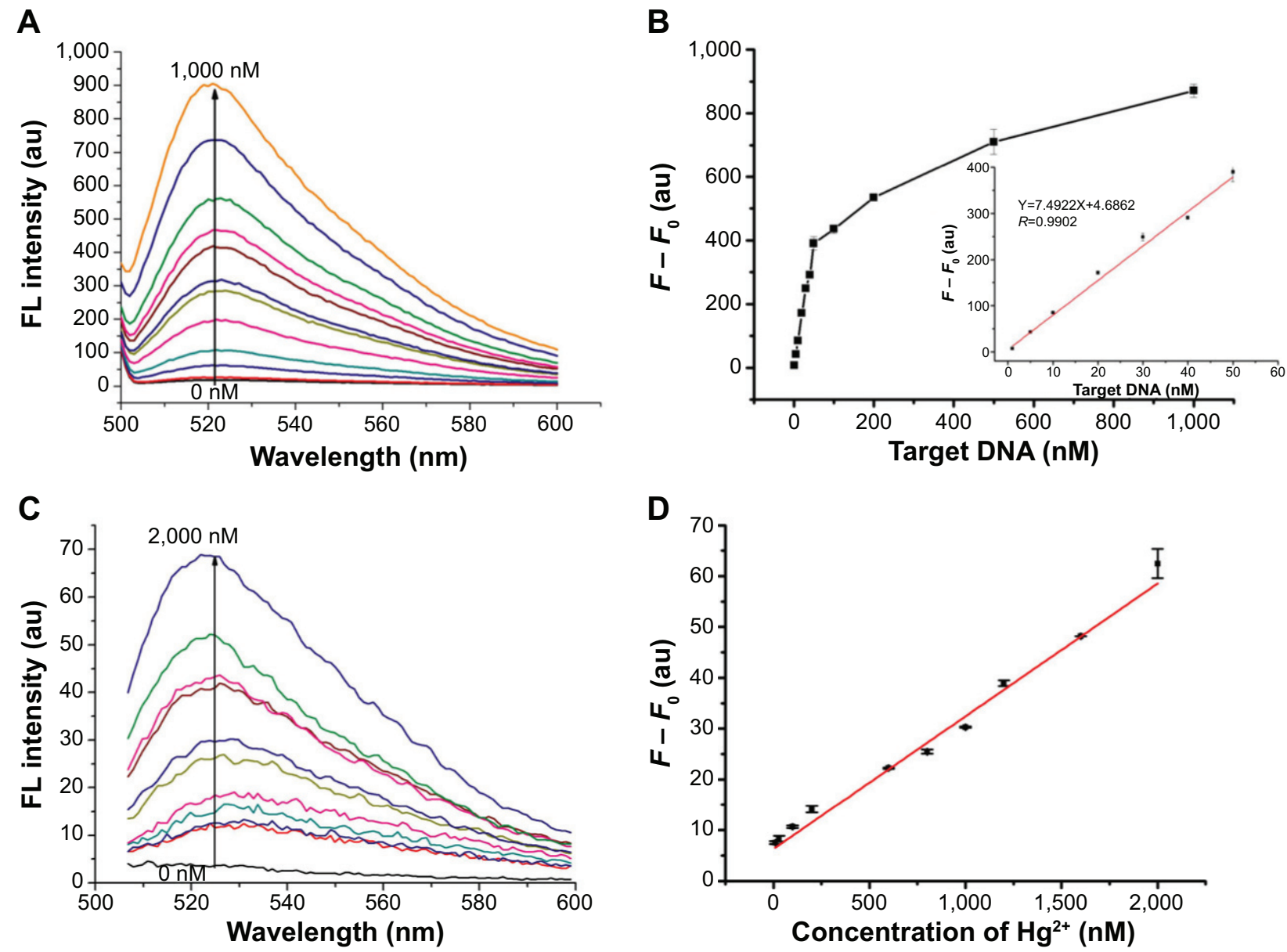

Figure 6 Fluorescence spectra $(\mathbf{A}, \mathbf{C})$ and the changeable fluorescence intensities $(\mathbf{B}, \mathbf{D})$ towards different concentrations of MDRI gene $(\mathbf{A}, \mathbf{B})$ and $\mathrm{Hg} \mathrm{g}^{2+}(\mathbf{C}, \mathbf{D})$.

Notes: (A) Fluorescence spectra of $8 \mu \mathrm{L} \mathrm{SGI}, 50 \mathrm{nM} \mathrm{CP}$, and $2 \mu \mathrm{g} / \mathrm{mL}$ GO upon addition of various concentrations of MDRI gene. (B) Values of $\Delta F=F-F_{0}$ for different concentrations of MDRI gene. Inset: calibration plot of $F-F_{0}$ against the concentration of target MDRI gene from $0 \mathrm{nM}$ to $50 \mathrm{nM}$. (C) Fluorescence spectra of $8 \mu \mathrm{L}$ SGI, $80 \mathrm{nM} \mathrm{MC}$, and $2 \mu \mathrm{g} / \mathrm{mL} \mathrm{GO}$ upon the addition of various concentrations of $\mathrm{Hg}^{2+}$. (D) Calibration plot of $F-F_{0}$ against the concentration of target $\mathrm{Hg}{ }^{2+}$ from $0 \mathrm{nM}$ to 2,000 $\mathrm{nM}$. Error bars represent standard deviations of measurements $(n=3)$.

Abbreviations: FL, fluorescence; au, arbitrary units; SGI, SYBR Green I; CP, capture probe; GO, graphene oxide; MDRI, multidrug resistance protein I; Hg², mercury ion; MC, mercury captures. 
features of the gene assay indicated its high convenience and cost efficiency. To verify the universal applicability of the proposed sensing strategy, $\mathrm{Hg}^{2+}$ was also monitored using the same approach. Figure $6 \mathrm{C}$ reveals that the fluorescence intensity gradually increases with $\mathrm{Hg}^{2+}$ concentration from $0 \mathrm{nM}$ to $2,000 \mathrm{nM}$. $F-F_{0}$ and $\mathrm{Hg}^{2+}$ concentration exhibited a linear relationship (Figure 6D). The linear equation is given as:

$$
y=0.02612 \mathrm{C}_{\mathrm{Hg}^{2+}(\mathrm{nM})}+6.2976
$$

for $\mathrm{Hg}^{2+}$ concentration between 10 and 2,000 nM with $R=0.9953$ and LOD of $2.2 \mathrm{nM}$ based on $3 \sigma /$ slope. The LOD was lower than that of $5 \mathrm{nM}$ of the electrochemical biosensor for $\mathrm{Hg}^{2+}$ based on polydopamine coated reduced $\mathrm{GO},{ }^{24}$ and also lower than $20 \mathrm{nM}$ of the fluorescent sensor for $\mathrm{Hg}^{2+}$ based on DNA-functionalized silica nanoparticles. ${ }^{25}$ In addition, the LOD of the proposed method ( $2.2 \mathrm{nM}$ ) for $\mathrm{Hg}^{2+}$ was much lower than the US Environmental Protection Agency standard (10 $\mathrm{nM} \mathrm{Hg}^{2+}$ for potable water). The good linear relationship and relatively low LOD demonstrated that the method is a sensitive approach to monitor $\mathrm{Hg}^{2+}$ concentration in water bodies like rivers. Furthermore, the proposed method exhibited ease of operation, low operating costs, and environment-friendly procedures.

The specificity of the sensing strategy relied on the high selectivity of the chosen gene sequence. To assess the potential interference by other conditions, the specificities of the proposed method for MDR1 gene and $\mathrm{Hg}^{2+}$ were investigated through mutant genes and other metal ions. One-mismatch, three-mismatch, non-complementary DNA and control

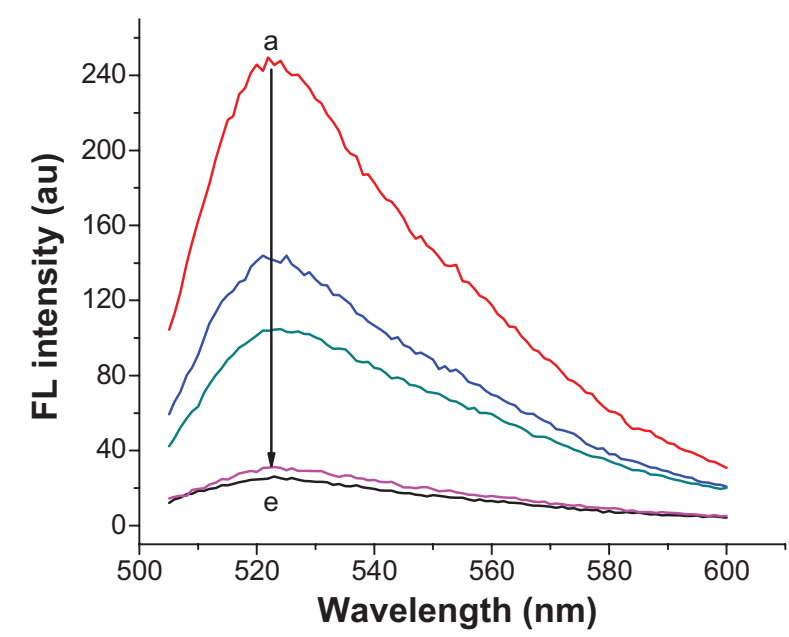

Figure 7 Fluorescence spectra from "a" to "e" for the addition of $20 \mathrm{nM}$ target, one-based mismatch, three-based mismatch, non-complementary MDRI gene and without any target in the test conditions of $8 \mu \mathrm{L} \mathrm{SGI}, 50 \mathrm{nM} \mathrm{CP}$, and $2 \mu \mathrm{g} / \mathrm{mL} \mathrm{GO}$. Abbreviations: FL, fluorescence; au, arbitrary units; MDRI, multidrug resistance protein I; SGI, SYBR Green I; CP, capture probe; GO, graphene oxide. blank were selected to analyze the specificity of MDR1 gene (Figure 7 and Figure S2A). The results indicated that only MDR1 gene markedly changed the fluorescence. In contrast to complementary sequences, one-mismatch sequence of MDR1 gene merely triggered half of the changes in fluorescence intensity. For $\mathrm{Hg}^{2+}$ selectivity, the method could be applied to test other 2,000 nM metal ions, such as $\mathrm{Cu}^{2+}, \mathrm{Fe}^{2+}, \mathrm{Ni}^{2+}, \mathrm{Ba}^{2+}, \mathrm{Cr}^{3+}$, $\mathrm{Pb}^{2+}, \mathrm{Mn}^{2+}, \mathrm{Co}^{2+}, \mathrm{Ce}^{2+}$, and $\mathrm{Ag}^{+}$compared with $2,000 \mathrm{nM} \mathrm{Hg}^{2+}$ (Figure S2B). Other metal ions yielded negligible effects in contrast to $\mathrm{Hg}^{2+}$, which possessed a high fluorescence intensity. These results suggested that no interference emanated from other metal ions in the sensing system for $\mathrm{Hg}^{2+}$ detection. The highly selective result for $\mathrm{Hg}^{2+}$ was attributed to the specific actions between $\mathrm{Hg}^{2+}$ and $\mathrm{T}$ to form $\mathrm{T}-\mathrm{Hg}-\mathrm{T}$ complexes. Overall, the selective results for MDR1 gene and $\mathrm{Hg}^{2+}$ confirmed the high specificity of signal-on fluorescence sensing.

\section{Real applications of the proposed method}

The feasibility of the proposed assay to real samples was evaluated by analyzing the MDR1 gene in $10 \%$ serum solution and testing the recovery of $\mathrm{Hg}^{2+}$ in actual water samples. The sensor was tested with known concentrations of MDR1 gene spiked in $10 \%$ serum for fluorescence detection. Figure 8 shows the fluorescence spectra of the proposed sensor in the presence of various concentrations of MDR1 gene in the serum. The fluorescence intensity at $520 \mathrm{~nm}$ gradually increased with the concentration of MDR1 gene. As shown in inset of Figure 8, the calibration curve of the fluorescence intensity against the concentration of MDR1 gene was found to be:

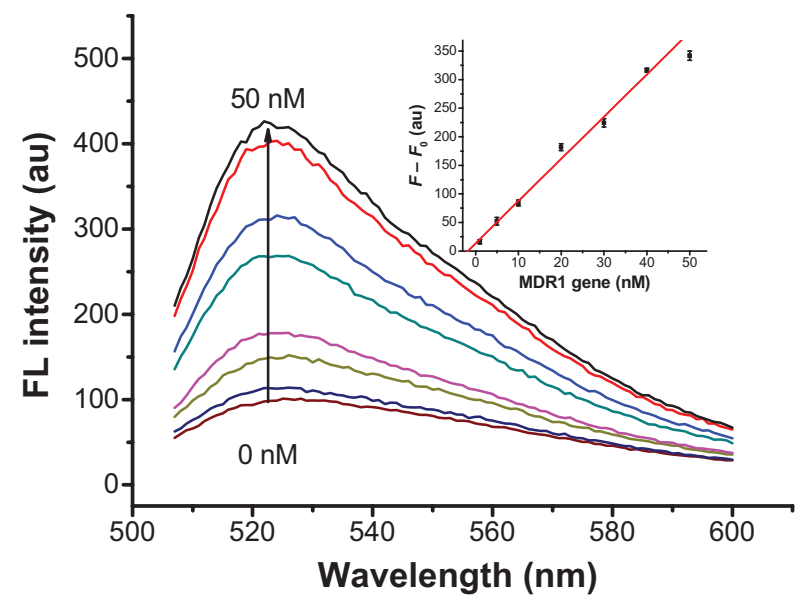

Figure 8 Fluorescence spectra and calibration plot (inset) for $8 \mu \mathrm{L} \mathrm{SGI}, 50 \mathrm{nM}$ $\mathrm{CP}$, and $2 \mu \mathrm{g} / \mathrm{mL} \mathrm{GO}$ toward various concentrations of MDRI gene from $0 \mathrm{nM}$ to $50 \mathrm{nM}$ in $10 \%$ serum.

Note: Error bars represent standard deviations of measurements $(n=3)$.

Abbreviations: FL, fluorescence; au, arbitrary units; MDRI, multidrug resistance protein I; SGI, SYBR Green I; CP, capture probe; GO, graphene oxide. 


$$
y=7.4001 \mathrm{C}_{\mathrm{TP}(\mathrm{nM})}+13.2151
$$

in which $R=0.9888$ and the slope of the calibration curve was 7.4001. Compared with the best-fit curve in Figure $6 \mathrm{~B}$ (with the slope of 7.4922), the proximity of the slope of the calibration curve in Figure 8B indicated that the proposed assay could accurately work to detect MDR1 gene in the serum.

For the actual $\mathrm{Hg}^{2+}$ detection system, two water samples were collected from Minjiang River and one sample was obtained from tap water in our laboratory. Then, the samples were analyzed with the proposed sensing system using standard addition methods. Prior to the addition of $60 \mathrm{nM}$ $\mathrm{Hg}^{2+}$, the fluorescence signals of the water samples were tested. The spiked samples with $60 \mathrm{nM} \mathrm{Hg}^{2+}$ were then added to three actual water samples to test the fluorescence signals through the proposed method. Fluorescence intensities before and after $\mathrm{Hg}^{2+}$ spiking were used to calculate the recovered $\mathrm{Hg}^{2+}$ concentrations according to the calibration equation (Figure 6D). The analytical results (Table 1) suggested that the recovery and precision of the proposed assay to detect $\mathrm{Hg}^{2+}$ in actual water samples were acceptable and satisfactory. The detection performance toward MDR1 gene and $\mathrm{Hg}^{2+}$ based on the sensing system was robust in complex matrices for distinct targets because of short testing times and simplicity in operation.

\section{Conclusion}

A robust and universal fluorescence sensing strategy was proposed to detect genes and metal ions. The principle of the assay relied on target-based turn-on fluorescence of SGI, which induced the formation of dsDNA or DNA with hairpin structures. GO was used as a platform to amplify the signal-to-background ratio and improve the sensitivity of the proposed assay. Under optimized conditions, the assay was successfully accomplished with low LODs of 0.5 and $2.2 \mathrm{nM}$ for quantitative detections of MDR1 gene and $\mathrm{Hg}^{2+}$, respectively. Furthermore, the strategy revealed the advantages in selectivity and actual applications toward the

Table I Results for determination of $\mathrm{Hg}^{2+}$ in actual water samples and recoveries of the test of $\mathrm{Hg}^{2+}$

\begin{tabular}{lllll}
\hline Samples & $\begin{array}{l}\text { Initial }^{\mathbf{a}} \pm \text { SD } \\
(\mathbf{n M})\end{array}$ & $\begin{array}{l}\text { Addition } \\
(\mathbf{n M})\end{array}$ & $\begin{array}{l}\text { Found }^{\mathrm{b}} \pm \text { SD } \\
(\mathbf{n M})\end{array}$ & $\begin{array}{l}\text { Recovery } \\
(\%)\end{array}$ \\
\hline 1 & $44.6 \pm 0.2$ & & $101.5 \pm 0.3$ & 94.8 \\
2 & $41.8 \pm 0.3$ & 60 & $94.4 \pm 0.1$ & 87.7 \\
3 & $8.4 \pm 0.1$ & & $64.6 \pm 0.5$ & 93.7
\end{tabular}

Notes: a Data were obtained from the average of three independent determinations, which were detected by the proposed method. ${ }^{\mathrm{b}} \mathrm{The}$ data represent the average of three independent determinations.

Abbreviations: $\mathrm{Hg}^{2+}$, mercury ion; $\mathrm{SD}$, standared deviation. detection of MDR1 gene and $\mathrm{Hg}^{2+}$. The detection protocol of the method exhibited simplicity of operation and cost efficiency. Finally, considering the further improvement, the sensing strategy can be extended into signal-on and signaloff types and applied to detect other important targets, such as proteins and small molecules, given the special design of the corresponding ssDNA or aptamer.

\section{Acknowledgments}

This work is supported by grants from the National High Technology and Development of China (863 Project: 2012AA022604), the National Natural Science Foundation of China (21275028), the Major Program of Medical and Health Foundation of Nanjing Military Region (12Z39), and the project to cultivate young talents in Fujian Province health system (2013-ZQN-JC-16).

\section{Disclosure}

The authors have no conflicts of interest to disclose.

\section{References}

1. Workman J Jr, Koch M, Veltkamp D. Process Analytical Chemistry. Anal Chem. 2005;77(12):3789-3806.

2. Li J, Huang Y, Wang DF, et al. A power-free microfluidic chip for SNP genotyping using graphene oxide and a DNA intercalating dye. Chem Commun (Camb). 2013;49(30):3125-3127.

3. Andersen CM, Mortesen G. Fluorescence Spectroscopy: A Rapid Tool for Analyzing Dairy Products. J Agric Food Chem. 2008;56(3) 720-729

4. Chen GW, Song FL, Xiong XQ, Peng XJ. Fluorescent Nanosensors Based on Fluorescence Resonance Energy Transfer (FRET). Ind Eng Chem Res. 2013;52(33):11228-11245.

5. Gonçalves MS. Fluorescent Labeling of Biomolecules with Organic Probes. Chem Rev. 2009;109(1):190-212.

6. Zhang Y, Zhang B, Liu F, Luo JW, Bai J. In vivo tomographic imaging with fluorescence and MRI using tumor-targeted dual-labeled nanoparticles. Int J Nanomedicine. 2014;9(1):33-41.

7. Qing ZH, He XX, Qing TP, et al. Poly(Thymine)-Templated Fluorescent Copper Nanoparticles for Ultrasensitive Label-Free Nuclease Assay and Its Inhibitors Screening. Anal Chem. 2013;85(24):12138-12143.

8. Zhang CY, Yeh HC, Kuroki MT, Wang TH. Single-quantum-dot-based DNA nanosensor. Nat Mater. 2005;4(11):826-831.

9. Qian ZS, Shan XY, Chai LJ, Ma JJ, Chen JR, Feng H. A universal fluorescence sensing strategy based on biocompatible graphene quantum dots and graphene oxide for the detection of DNA. Nanoscale. 2014; 6(11):5671-5674

10. Kong L, Xu J, Xu YY, Xiang Y, Yuan R, Chai YQ. A universal and label-free aptasensor for fluorescent detection of ATP and thrombin based on SYBR Green I dye. Biosens Bioelectron. 2013;42:193-197.

11. Wang J, Liu B. Highly sensitive and selective detection of $\mathrm{Hg}^{2+}$ in aqueous solution with mercury-specific DNA and Sybr Green I. Chem Commun (Camb). 2008;44(39):4759-4761.

12. He Y, Wang ZG, Tang HW, Pang DW. Low background signal platform for the detection of ATP: When a molecular aptamer beacon meets graphene oxide. Biosens Bioelectron. 2011;29(1):76-81.

13. Zhou DM, Xi Q, Liang MF, Chen CH, Tang LJ, Jiang JH. Graphene oxide-hairpin probe nanocomposite as a homogeneous assay platform for DNA base excision repair screening. Biosens Bioelectron. 2013;41:359-365. 
14. Hu K, Liu JW, Chen J, et al. An amplified graphene oxide-based fluorescence aptasensor based on target-triggered aptamer hairpin switch and strand-displacement polymerization recycling for bioassays. Biosens Bioelectron. 2013;42:598-602.

15. Lu CH, Yang HH, Zhu CL, Chen X, Chen GN. A graphene platform for sensing biomolecules. Angew Chem Int Ed Engl. 2009;48(26): 4785-4787.

16. Zhou J, Lu Q, Tong Y, Wei W, Liu SQ. Detection of DNA damage by using hairpin molecular beacon probes and graphene oxide. Talanta. 2012;99:625-630.

17. Li Z, Zhu WP, Zhang JW, Jiang JH, Shen GL, Yu RQ. A label-free amplified fluorescence DNA detection based on isothermal circular strand-displacement polymerization reaction and graphene oxide. Analyst. 2013;138(13):3616-3620.

18. Zhang Y, Liu Y, Zhen SJ, Huang CZ. Graphene oxide as an efficient signal-to-background enhancer for DNA detection with a long range resonance energy transfer strategy. Chem Commun (Camb). 2011;47(42):11718-11720.

19. Nooter K, Herweijer H. Multidrug resistance (MDR) genes in human cancer. Br J Cancer. 1991;63(5):663-669.
20. Kitada K, Yamasaki T. The MDR1/ABCB1 regional amplification in large inverted repeats with asymmetric sequences and microhomologies at the junction sites. Cancer Genet Cytogenet. 2007;178(2): 120-127.

21. Su LL, Cheng CY, Mruk DD. Drug transporter, P-glycoprotein (MDR1), is an integrated component of the mammalian blood-testis barrier. Int J Biochem Cell Biol. 2009;41(12):2578-2587.

22. Marcano DC, Kosynkin DV, Berlin JM, et al. Improved Synthesis of Graphene Oxide. ACS Nano. 2010;4(8):4806-4814.

23. Liu Y, Wang YX, Jin JY, Wang H, Yang RH, Tan WH. Fluorescent assay of DNA hybridization with label-free molecular switch: reducing background-signal and improving specificity by using carbon nanotubes. Chem Commun (Camb). 2009;45(6):665-667.

24. Zhang Y, Zhao H, Wu ZJ, et al. A novel graphene-DNA biosensor for selective detection of mercury ions. Biosens Bioelectron. 2013; 48:180-187.

25. Zhang YF, Yuan Q, Chen T, Zhang XB, Chen Y, Tan WH. DNACapped Mesoporous Silica Nanoparticles as an Ion-Responsive Release System to Determine the Presence of Mercury in Aqueous Solutions. Anal Chem. 2012;84(4):1956-1962. 


\section{Supplementary materials}

A

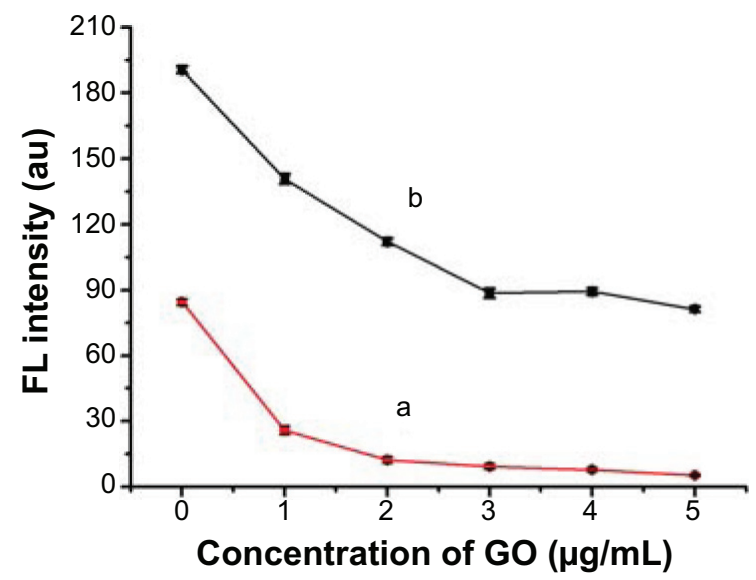

B

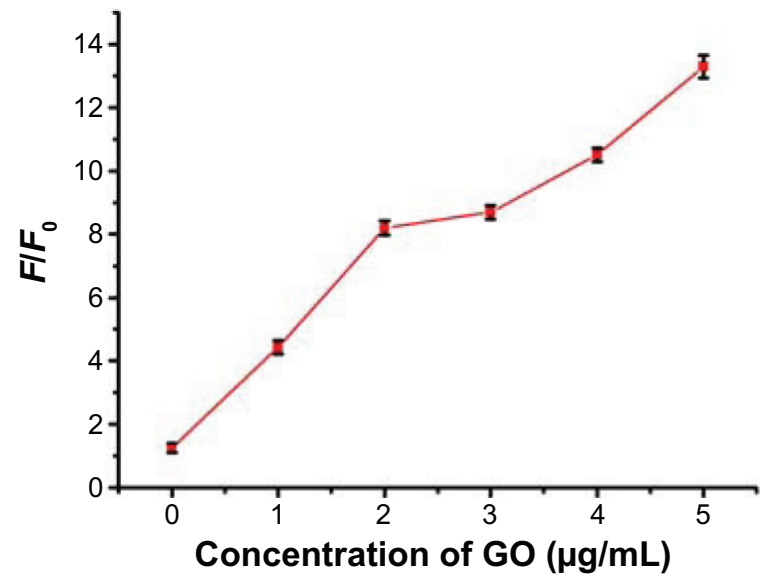

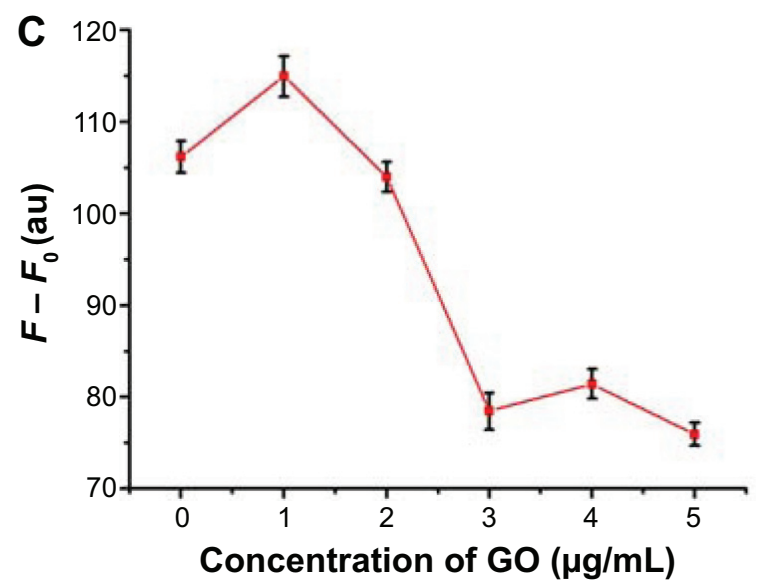

Figure SI Influence of different concentrations of GO on (A) the changeable fluorescence intensity with the absence (a) and presence (b) of I0 nM Target DNA, (B) the ratio of the fluorescence intensities, and (C) the difference of SGI at $520 \mathrm{~nm}$ in the absence and presence of $10 \mathrm{nM}$ target DNA.

Notes: The concentration of SGI in the test was $0.79 \mu \mathrm{M}$. Error bars were the standard deviation of the three replicate determinations. Abbreviations: GO, graphene oxide; au, arbitrary units; SGI, SYBR Green I; FL, fluorescence.

A

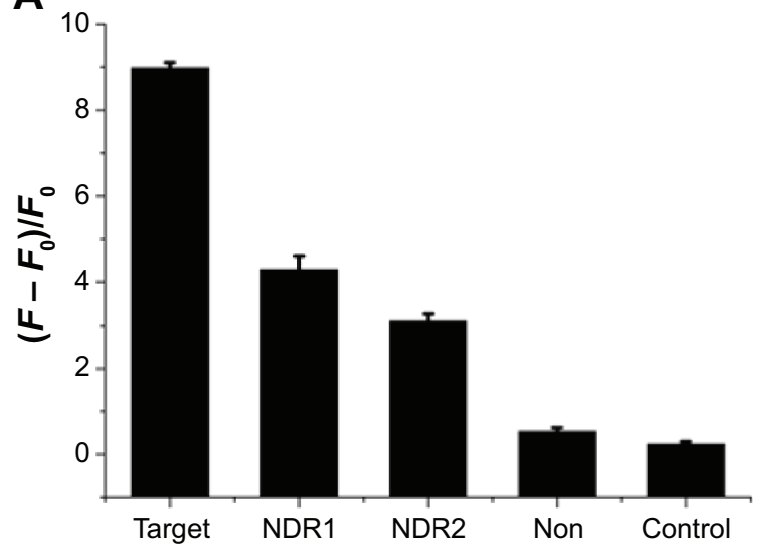

B

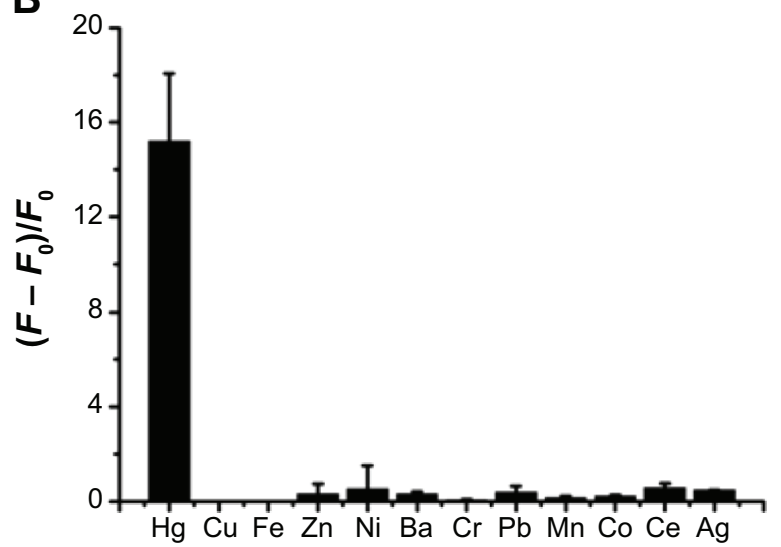

Figure S2 (A) Fluorescence intensities for $8 \mu \mathrm{L} \mathrm{SGI,} 50 \mathrm{nM} \mathrm{CP}$, and $2 \mu \mathrm{g} / \mathrm{mL}$ GO upon addition of $20 \mathrm{nM}$ target, one-based mismatch, three-based mismatch, noncomplementary MDRI gene, and without any target. (B) Selectivity evaluation of $8 \mu \mathrm{L} \mathrm{SGl,} 80 \mathrm{nM} \mathrm{MC}$, and $2 \mu \mathrm{gL} / \mathrm{mO}$ toward $2,000 \mathrm{nM} \mathrm{Hg}{ }^{2+}$ and other ions.

Abbreviations: MDRI, multidrug resistance protein I; SGI, SYBR Green I; CP, capture probe; GO, graphene oxide; $\mathrm{Hg}^{2+}$, mercury ion; MC, mercury captures; NDR, non multidrug resistance protein. 


\section{Publish your work in this journal}

The International Journal of Nanomedicine is an international, peerreviewed journal focusing on the application of nanotechnology in diagnostics, therapeutics, and drug delivery systems throughout the biomedical field. This journal is indexed on PubMed Central, MedLine, CAS, SciSearch $\AA$, Current Contents $\AA /$ Clinical Medicine,

Journal Citation Reports/Science Edition, EMBase, Scopus and the Elsevier Bibliographic databases. The manuscript management system is completely online and includes a very quick and fair peer-review system, which is all easy to use. Visit http://www.dovepress.com/ testimonials.php to read real quotes from published authors.

Submit your manuscript here: http://www.dovepress.com/international-journal-of-nanomedicine-journal 